\section{DR. WILLIAM HANAFEE}

$t$ is our deepest sorrow and sadness to inform all of the recent death of Dr. William N. Hanafee, a founding member of the American Society of Neuroradiology (ASNR) and the American Society of Head and Neck Radiology (ASHNR). Dr. Hanafee died in Pauma Valley, California, after battling a series of cerebral infarctions with great dignity and his characteristically great resolve, on August 19, 2009. He was 83 years of age and surrounded by those he loved at his passing. He is survived by his beloved wife, Mrs. Constance (Connie) Hanafee, and their 4 children, Bill Jr, Linda, Michael, and Patrick and many grandchildren.

Bill Hanafee grew up in the Midwest, a native of Louisville, Kentucky. He completed his undergraduate studies at the University of Rochester, New York, and medical school at the University of Louisville. He later served in the US Navy, both as an intern and subsequently as a lieutenant while on leave from the University of California, Los Angeles (UCLA). Bill spent most of his career at UCLA, where he was a resident, staff radiologist, academician, and scientist. He completed a fellowship in neuroradiology at the University of Gothenburg in Sweden, where he extensively studied the newly emerging field of angiographic diagnosis in diseases of the brain, head, and neck. He also studied conventional angiography with Dr. Per Amundsen in Norway.

Bill was an integral member of the group of pioneering radiologists who started the subspecialty practice of neuroradiology in the United States. With a few other visionaries, Bill helped introduced the technique of transfemoral cerebral angiography, which he learned in Sweden, to the United States in the 1960s. Bill was an innovator throughout his life. His 5F "Hanafee" catheter, a pioneering step in the run-up to microcatheter technology, became a standard and is still used in practice throughout the world. Before the introduction of these newer techniques, surgeons performed angiographic procedures via direct puncture; however, the morbidity from cerebral angiography in the United States was an unacceptable $20 \%$. When Dr. Hanafee returned from Sweden to UCLA, he was slowly able to convince referring clinicians of his expertise and the safety of these new angiographic techniques. A combined study between UCLA and the University of California, San Francisco, where Hans Newton had introduced femoral conventional angiography as well, showed that using the new Seldinger technique of cerebral angiography via the femoral approach decreased the morbidity at the 2 institutions to $0.3 \%$. Because of Bill's vision, creativity, and pragmatism, he became one of the founding members of the ASNR and made a lasting contribution to that society and to thousands of patients around the world.

Dr. Hanafee was Chairman of the Department of Radiology at UCLA, where he maintained phenomenal academic productivity while teaching many residents and fellows who subsequently went on to illustrious academic careers. He had a vision for radiologic research and established the Leo G. Rigler Center for Radiologic Sciences at UCLA. He published more than 300 peer-reviewed articles and gave numerous lectures worldwide. In 1974, when Dr. Hanafee stepped down as Chairman of Radiology at UCLA, he began a second career as a head and neck radiologist. He convinced Dr. Paul Ward, the Chief of Otolaryngology at UCLA, to assign his chief resident to sit at his side for the next 5 years to provide clinical information about the patients whose head and neck films he was interpreting. How is that for the way to learn head and neck radiology! This approach to learning and interpreting studies in the clinical context is the greatest gift he has passed to his many students.

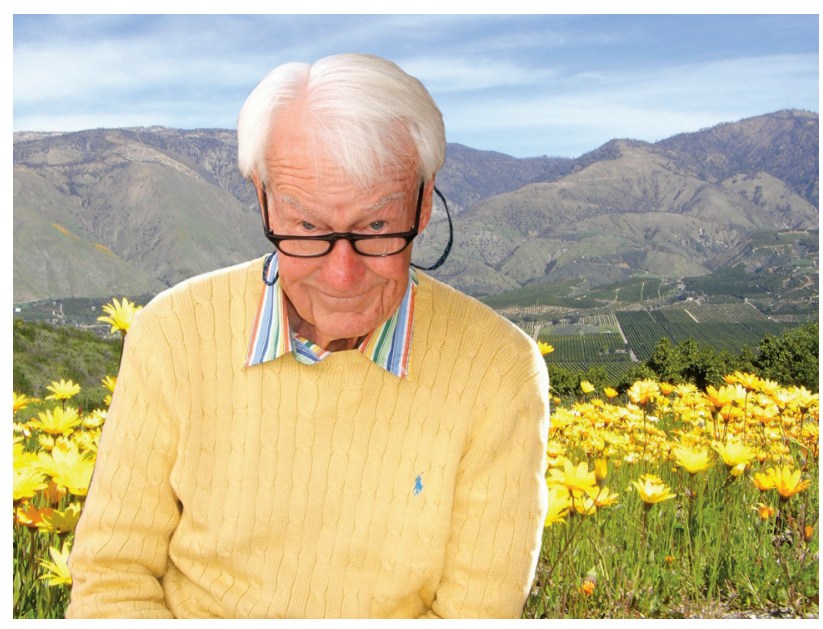

In the late 1970s, Bill partnered with Drs. Dino Valvassori, Guy Potter, and Stormy Johnson to found the ASHNR. This organization, which now counts over 500 members, has done more than any other single entity to elevate the quality of care in patients with often devastating diseases. In 1982, he coauthored Computed Tomography of the Head and Neck (Williams and Wilkins), a classic reference text and one of the first textbooks detailing cross-sectional anatomy and pathology of the head and neck. In 2001, the ASHNR honored Dr. Hanafee's contributions and achievements with its first Gold Medal. His commitment and determination as cofounder of ASHNR have lead to tremendous strides in the development of head and neck radiology as a subspecialty.

Dr. Hanafee was not only a great teacher but also an amazing storyteller. He might spend 30-45 minutes discussing 1 case (in the good old days), and the session would always end with great laughter and learning points. He loved to imitate different types of hoarseness produced by glottic and supraglottic cancers. Many clinicians visited his office with jackets of films in hand, and Bill usually provided an answer. He would often say: "Giving clinicians 10 differential diagnosis possibilities would not help them. It is useless to say that it could be tumor, or could be infection. Give them a few possibilities and suggest what the next step should be."

Connie and Bill Hanafee retired to a lovely home along a beautiful golf course in Pauma Valley, California. In his retirement, Bill played golf every day for 17 years with Paul Ward, former Chairman of Otolaryngology/Head and Neck Surgery at UCLA and his lifetime friend. According to Connie, they were known on the course as the "pair of docs."

Bill Hanafee had a special gift of choosing the right path and then walking that path with great humility and love. Those of us touched by him now have the responsibility of honoring this wonderful physician and human being by extending his teachings, passion, and vision, mixed with his wonderful prag- 
matism, to future generations. William Hanafee will be deeply missed, but he leaves a tremendous legacy through his work and through those he influenced personally and academically.

W. Dillon

University of California, San Francisco

Y. Anzai

University of Washington

A. Mancuso

University of Florida, Gainsville

DOI 10.3174/ajnr.A1966 